\title{
Back to the Future, Part II
}

\section{This year is the $50^{\text {th }}$ anniversary of the activation of the Arpanet project. The first packet switches (called Interface Message Processors or IMPs) were installed at UCLA,}

SRI International [then Stanford Research Institute], UC Santa Barbara, and University of Utah. Host computers at UCLA and SRI made their first connection through the Arpanet on October 29, 1969.

Tom Standage's book, The Victorian Internet, ${ }^{\text {a }}$ highlights the drama of the arrival of the telegraph in the mid- $19^{\text {th }}$ century. In its earliest incarnation, telegraph operators coded text messages in Morse Code ${ }^{b}$ and sent them to the next operator whose receiver was connected on a dedicated, point-to-point wire. The transcribed message was then re-sent by the receiving operator to the next one, proceeding hop-by-hop until it reached the final operator who transcribed the message and delivered it to the recipient, typically by courier. This was called a "store-and-forward" messageswitching system because at each hop, messages were temporarily stored at the intermediate telegraph operator's office until they could be re-sent to the next operator. ${ }^{c}$

When teletype machines were invented, they punched holes in paper tape coded with 5 bits to represent up to 32 characters or symbols. Eventually an 8-bit coding scheme was used to expand the available character set to include uppercase and lowercase

\footnotetext{
a T. Standage. The Victorian Internet. Walker \& Company, 1998; ISBN-13: 978-162040592, ISBN10: $162040592 X$, ISBN 0-8027-1342-4 (hardcover), ISBN 978-0-8027-1604-0 (paperback).

b https://en.wikipedia.org/wiki/Morse_code

c For more information, see my June 2019 Cerf's Up column.
}

as well as other special characters. An operator would enter a message on the teletype and a paper tape would be punched. The operator would tear off the paper tape and hang it on a peg next to the teletype that would be used to send the message to the next hop. This was called a "torn tape" system since the punched paper tapes would be torn from the originating teletype and fed into a teletype that would automatically read the tape and send the signals to the next teletype. The receiving teletype, which was connected by a dedicated circuit, would then punch out a copy of the message on a tape which would again be torn from the machine ...

Interestingly, the telephone emerged from research attempting to allow one wire to carry more than one telegraph message at the same time. Telephone circuits were built manually with patch panels to connect the caller to the called party. Eventually automatic switching was possible and circuits were built automatically from source to destination. This allowed teletypes to be directly connected end-to-end without requiring intermediate queueing. No more store-and-forward was necessary as the two end-points were directly connected by a circuit.

Returning to the Arpanet, the challenge there was to find an alternative to connecting the machines by way of dial-up circuits. Such a process would have been painfully slow since each connection would take seconds to complete while the computers, even in the $1960 \mathrm{~s}$, were operating at microsecond speeds. Ironically, the solution was to abandon the circuit switching concept that had been so effective for the teletype system and introduce a store-and-forward packet switching system! Since the circuits connecting the packet switches were fixed and dedicated, there was no circuit switching delay. Rather, packets from the host computers could be sent as soon as they were ready to the directly connected packet switch, which would forward them in milliseconds to the next packet switch, completing the hop-by-hop journey in tens of milliseconds. In the original Arpanet, the dedicated circuits were operated at 50 kilobits/second, so a 1,000-bit packet would take 20 milliseconds to transmit, per hop. A five-hop transmission would consume 100 milliseconds.

The subsequent Internet made use of circuits running at a minimum of 1.5 megabits/second in the early 1980s and today at 100-400 gigabits/ second. The transmission delays are negligible, per hop, and are dominated by speed of light and/or queueing delays in the event of congestion. So we have come full circle back to the store-and-forward days of the telegraph, but at sub-nanoseconds of transmission delay per bit. We've gone back to the future!

Vinton G. Cerf is vice president and Chief Internet Evangelist at Google. He served as ACM president from 2012-2014. 